\title{
Ecophysiology of Carpobrotus rossii in Tasmania: Linking plant's antioxidant pctivity with a natural habitat
}

\author{
*Adam Pirie, **Sergey Shabala, **David Parsons, *Christian Narkowicz, \\ *Glenn Jacobson, *** Jolanda Renggli \\ *School of Pharmacy, University of Tasmania, Private bag 54, Hobart, Tas 7001, Australia \\ e-mail: Adam.Pirie@utas.edu.au \\ **School of Agricultural Science, University of Tasmania, Private bag 54, Hobart, Tas 7001, Australia \\ ***University of Basel, Petersplatz 1, CH-4003 Basel, Switzerland
}

\begin{abstract}
Summary. Flavonoids extracted from Carpobrotus rossii possess cardioprotective activity and as such there is interest in maximising the per plant yield of these compounds. This field study was undertaken to determine the environmental variables driving flavonoid production. Results suggest that production of tannin and flavonoid metabolites is not controlled by a single variable alone, but through an interplay of variables linked to oxidative stress in the plant.
\end{abstract}

Key words: flavonoid, tannin, oxidative stress.

\section{Introduction}

The Australian native plant Carpobrotus rossii or "pigface” (Fig. 1) is a succulent glaborous halophytic perennial commonly found in the coastal foredunes of southern Australia (Venning 1984). Recent investigations conducted in the School of Pharmacy, University of Tasmania (Australia) have shown that extracts from this plant have high antioxidant activity and contain novel flavonoid compounds with cardio-protective activities (Geraghty et el. 2010). These flavonoids have the potential to be developed into a pharmaceutical or nutraceutical product, but at present the conditions required to maximise flavonoid production in this species are unknown. This study aimed to assess variation in metabolite (tannin and flavonoid) production and identify the factors driving this variation.

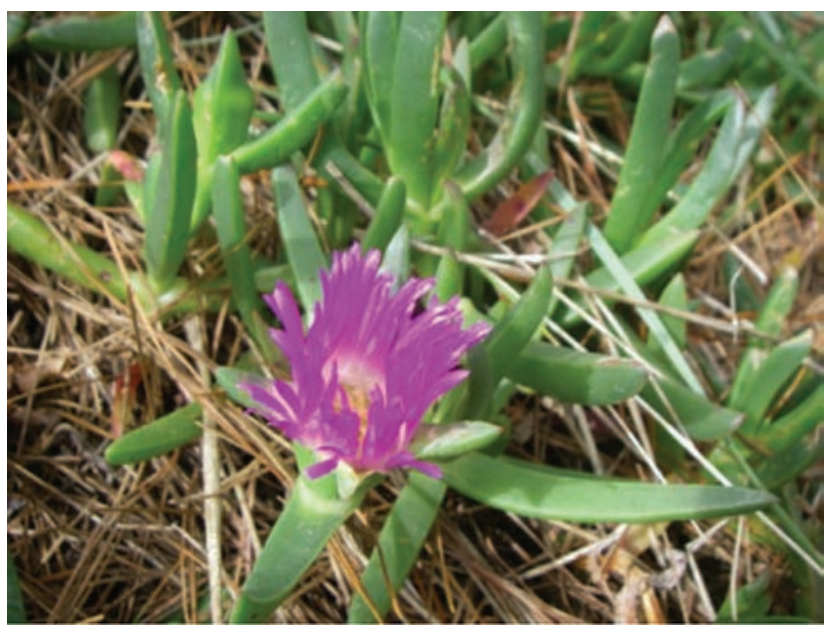

Figure 1. Carpobrotus rossii flower and leaf 


\section{Study location}

16 locations along the Tasmanian coastline were surveyed with a total of 73 plants collected in total.

\section{Methods}

Plant (leaf sap $\mathrm{K}, \mathrm{Na}$ and $\mathrm{Cl}$ composition and osmolality; chlorophyll fluorescence characteristics; stomatal density), soil ( $\mathrm{pH}$; EC; $\mathrm{Na}$ and $\mathrm{K}$ content) and environmental (temperature; rainfall; radiation) characteristics were measured for each location. Flavonoid and tannin production were assessed using HPLC with UV detection. Pearsons correlations were used to identify those variables most related to flavonoid and tannin production. Multiple regressions were subsequently performed with these variables to develop models predicting plant flavonoid and tannin production.

\section{Results}

Great variation in flavonoid and tannin production was observed between the collection sites (Fig. 2). Pearsons correlations showed no single variable with significant correlation to both flavonoid and tannin production (data not shown). However multiple factor regression models were able to predict production levels with some accuracy. The best 4 factor predictive models for flavonoid production contained soil potassium, stomatal density, radiation, and rainfall volume. Whilst the best prediction model of tannin production contained soil potassium, stomatal count, sap osmolality evaporative moisture loss. These prediction models had adjusted $r^{2}$ of 0.55 or higher.

\section{Discussion}

Tannins and flavonoids are two major classes of non-enzymatic antioxidants in plants. Their production is known to increase dramatically under oxidative stress conditions to maintain the proper balance of reactive oxygen species (ROS) and protect photosynthetic and cellular machinery from permanent damage (Hernandez et al. 2009). Within the cell, chloroplasts are arguably the major site of ROS production; various abiotic stresses lead to the increased accumulation of ROS in this organelle. Among these, excessive radiation levels (especially the UV component), high salinity, and drought are considered to be the most crucial (Hernandez et al. 2009; Scalabrelli et al. 2007). It is not surprising, therefore, that both flavonoid and tannin production in $C$. rossii were strongly correlated with both radiation and soil water availability level at different sites. Interestingly, it was a combination of factors but not one

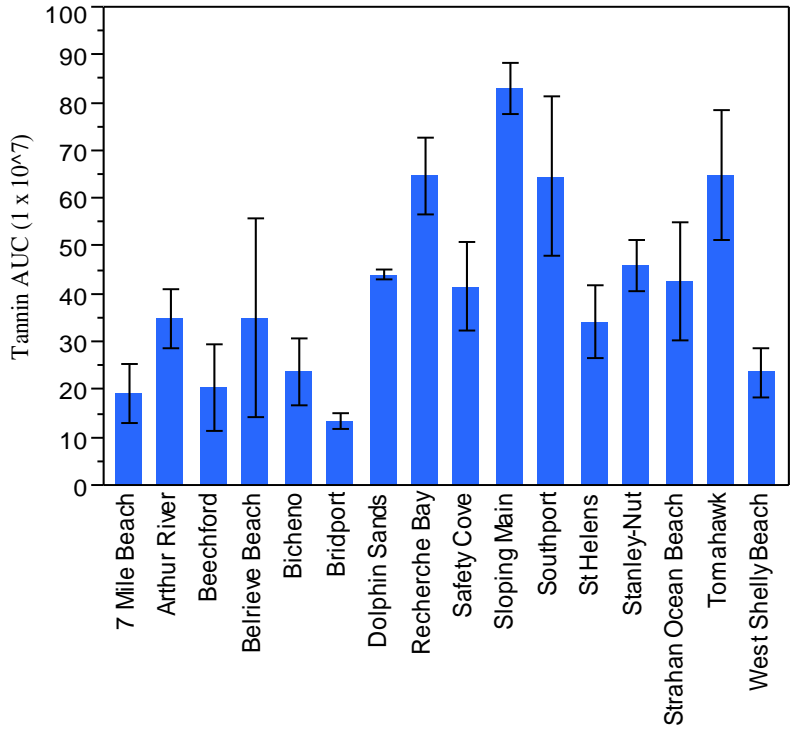

Location

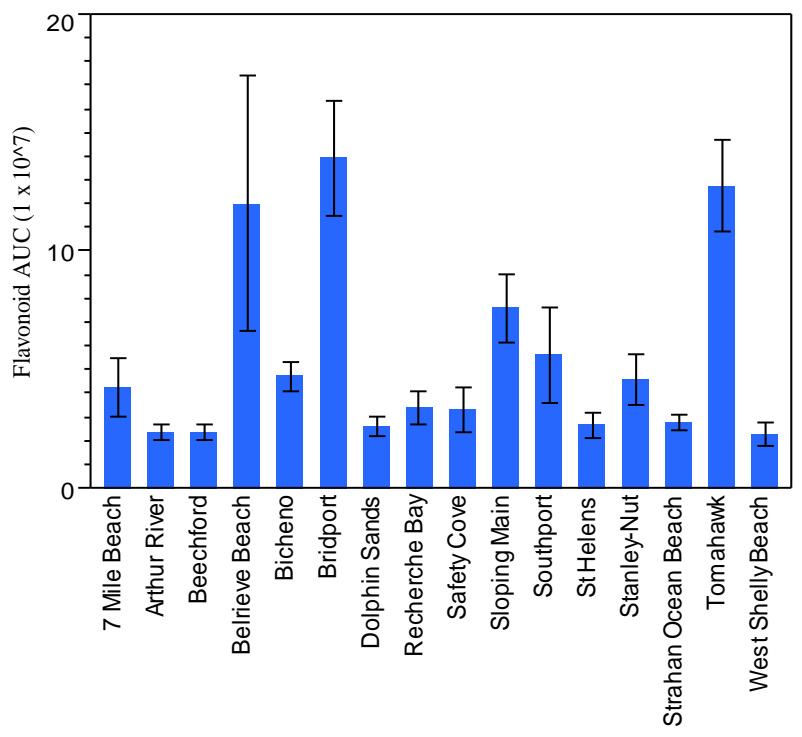

Location

Figure 2. A - Mean Flavonoid production per site $(n=3-5)$ B - Mean Tannin production per site $(n=3-5)$. Mean results \pm standard errors shown.

factor per se, that enhanced antioxidant biosynthesis in $C$. rossii.

It is also interesting that both flavonoid and tannin production were negatively correlated with soil $\mathrm{K}^{+}$content. Intracellular potassium homeostasis is considered to be essential for cell metabolic activity, and a decrease in cytosolic $\mathrm{K}^{+}$level may even led to a programmed cell death (Shabala 2009). It could be suggested that increased tannin production under low soil $\mathrm{K}^{+}$conditions may be needed 
to prevent further ROS-induced $\mathrm{K}^{+}$leak (Demidchik et al. 2010 ) in order to maintain cell viability. The causal relationship between flavonoid production and stomatal density requires more investigation. Taken together, this study shows that multiple factors control antioxidant production in $C$. rossi under the natural habitat, and calls for the need to conducted experiments under controlled conditions to reveal the major factors responsible for the observed variation in flavonoid and tannin production.

\section{References}

Demidchik V., Cuin T. A., Svistunenko D., Smith S. J., Miller A. J., Shabala S., Sokolik A. \& Yurin V., 2010, Arabidopsis root $\mathrm{K}^{+}$efflux conductance activated by hydroxyl radicals: single-channel properties, genetic basis and involvement in stress-induced cell death, Journal of Cell Science 123: 1468-1479.

Geraghty D., Jacobson G., Narkowicz C., Shing C. \& Pirie A., 2010, Effect of chronic Carpobrotus rossii (pigface) ingestion on systolic blood pressure, body weight, blood lipids, haematological profile and in vitro vascular function in adult male rats, Proceedings of ASCEPT. Dec. 2010, Melbourne: 36.

Hernandez I., Alegre L., Van Breusegem F. \& MunneBosch S., 2009, How relevant are flavonoids as antioxidants in plants?, Trends in Plant Science 14 (3): $125-132$.

Scalabrelli G., Saracini E., Remorini D., Massai R. \& Tattini M., 2007, Changes in leaf phenolic compounds in two grapevine varieties (Vitis vinifera L.) grown in different water conditions, [in:] V. Nuzzo, P. Giorio, C. Giulivo (eds.), Proceedings of the International Workshop on Advances in Grapevine and Wine Research: 295-299.

Shabala S., 2009, Salinity and programmed cell death: unravelling mechanisms for ion specific signalling, Journal of Experimental Botany 60 (3): 709-711.

Venning J., 1984, Carpobrotus, [in:] Flora of Australia, vol. 4: Phytolaccaceae to Chenopodiaceae, (Australia BoFaF, ed.), Australian Government Publishing Service Canberra. 